\title{
DOI 10.26886/2414-634X.6(25)2018.10
}

UDC: 72.01

\section{ADVERTISING INTERVENTIONS IN METRO ARCHITECTURAL SPACE}

\section{Ya. Averbakh, PhD in Architecture}

Kharkiv National University of Civil Engineering and Architecture, Ukraine, Kharkiv

Research actualizes the problem of uncontrolled distribution of advertising messages in the architectural environment, namely in the underground metro space, as exemplified by the Kharkiv and Kyiv metro stations. Particular attention is focused on the so-called branding - a campaign involving the complete covering of architectural forms and structures with advertising images. The result of the negative influence of such methods on the perception of the architectural image of metro stations is shown. As a result of analysis of the current state of the metro in the cities of the post-Soviet space, it has been revealed that the identified problem is characteristic only for Ukraine. The need is noted to involve professionals and the public to discuss and further resolve this problem.

Key words: architectural environment, evaluation of aesthetic qualities, outdoor advertising, commercial signs, metro space.

кандидат архитектуры Авербах М. Я. Рекламные интервенции в архитектурном пространстве метрополитена/ Харьковский национальный университет строительства и архитектуры, Украина, Харьков

Исследование актуализирует проблему безудержного распространения рекламных сообщений в архитектурной среде, $в$ частности в подземном пространстве метро на примере станций харьковского и киевского метрополитенов. Особое внимание сосредоточено на так называемом брендировании - акции, которая предусматривает полное завешивание архитектурных фрорм и конструкций рекламными изображениями. Показан результат негативного влияния таких приемов на восприятие архитектурного образа станций метро. В результате анализа существующего состояния метрополитенов городов постсоветского пространства выявлено, что обозначенная проблема является характерной только для Украины. Отмечается необходимость привлечения профрессионалов и общественности для обсуждения и дальнейшего урегулирования данной проблемы.

Ключевые слова: архитектурная среда, оченка эстетических качеств, наружная реклама, коммерческие знаки, пространство метрополитена. 
Введение. Вездесущая реклама распространилась практически во всех сферах человеческой активности, и как следствие - в визуальном пространстве современного города, порой «перехвативши инициативу» у архитектуры. С сожалением можно констатировать, что визуальный образ архитектурной среды в значительной степени становится рекламным. Проблема загрязнения визуального пространства рекламными формами весьма непростая, поскольку реклама с давних времен сопровождала городскую среду, развиваясь вместе с ней, и сегодня является неотъемлемой частью современной цивилизации [1]. Изобретательные рекламисты приспособили каждый уголок городской среды для распространения рекламных сообщений. Это - всевозможные щиты различных размеров и конфигураций, отдельно стоящие вдоль улиц и пешеходных аллей, на площадях и перекрестках, установленные на опорах мостов и крышах домов, налепленные на заборах и фасадах. Это - вывески, указатели, стелы, витрины, перетяжки, штендеры, вымпелы, постеры и многое другое. Перенасыщение городского пространства коммерческими знаками вызывает объяснимое недовольство горожан. Этой проблеме посвящаются теоретические труды ученых-исследователей. Среди них работы доктора Анны Кронин (Anne Cronin), докторов наук в области городского планирования Джека Насара и Ксиаодонга Хонга (Jack L. Nasar \& Xiaodong Hong), профрессора Школы архитектуры университета Ливерпуля Ричарда Коека и профессора Манчестерского университета Гари Варнаби (Richard Koeck \& Gary Warnaby), доктора в области городского дизайна Адрианы Портеллы (Adriana Portella). Местные власти разрабатывают правила размещения наружной рекламы в городе, прибегают к попыткам ограничить еe распространение. Эти попытки не приводят к желаемому результату, а между тем реклама нашла себе новое место для паразитирования, она забралась под землю.

Целью данного исследования является раскрыть и описать фракты экспансии рекламных изображений в подземном пространстве метрополитена, вскрыть конфоликт между архитектурным образом станций метро и их «рекламным образом».

\section{Изложение основного материала.}

Достаточно закрытый для критики и общественного обсуждения метрополитен стал продавать за рекламу свои пространства и фрормы, и очень в этом преуспел. Материальный стимул вполне понятен. Задействованы все места, где пребывает пассажир - входные вестибюли, переходы, станции, подвижной состав снаружи и внутри. Залеплены стены, двери, окна, пол, ступени и перила лестниц, своды эскалаторных тоннелей. Операторы наружной рекламы предлагают рекламные места внутри вагона и вне его (рис. 1). 


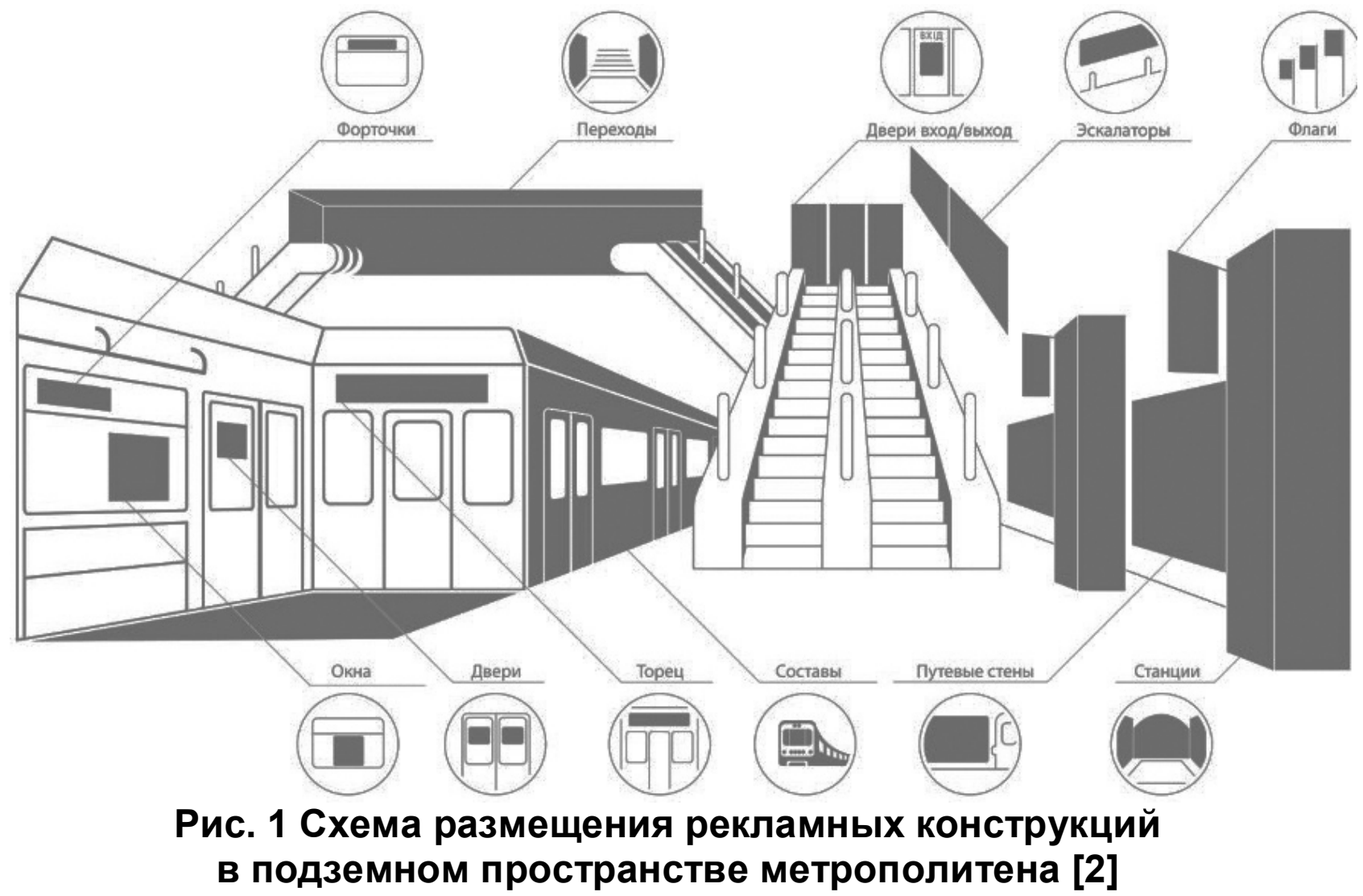

В вагоне размещаются аппликации на простенках, скосах, дверях и схеме метрополитена в фрорматах A3, A4 или 42x13, а также рекламными блоками $(13 \times 10 \mathrm{~cm}, 13 \times 13 \mathrm{~cm}, 13 \times 21 \mathrm{~cm})$. Вне вагона используются следующие виды рекламных материалов: щиты вдоль эскалаторов, постеры вдоль станционных платорорм, щиты в вестибюлях и переходах, лайтбоксы, реклама на световых инфрормационных указателях, на схеме метрополитена, рекламноинформационные установки, стикеры на витражах, напольная липкая аппликация [3]. Однако наиболее агрессивной и циничной фоомой распространения рекламы в метро является так называемое брендирование - такой прием, когда рекламными изображениями, представляющими собой единый сюжет и отображающими визуальные константы определенного бренда, покрывают полностью формы и конструкции непосредственно внутри распределительного вестибюля станции. В статье «Брендирование станций харьковского метрополитена. Взгляд с позиции архитектора» [4] были представлены характеристики пяти станций («Площадь конституции», «Исторический музей», «Героев труда», «Пушкинская» и «Университет»), подвергшихся брендированию, проведен сравнительный анализ архитектурного образа этих станций в первозданном виде и в результате завешивания рекламными изображениями, выявлена связь между типологическими особенностями станций, связанными с их конструкцией, и приемами рекламного оформления (рис. 2). 


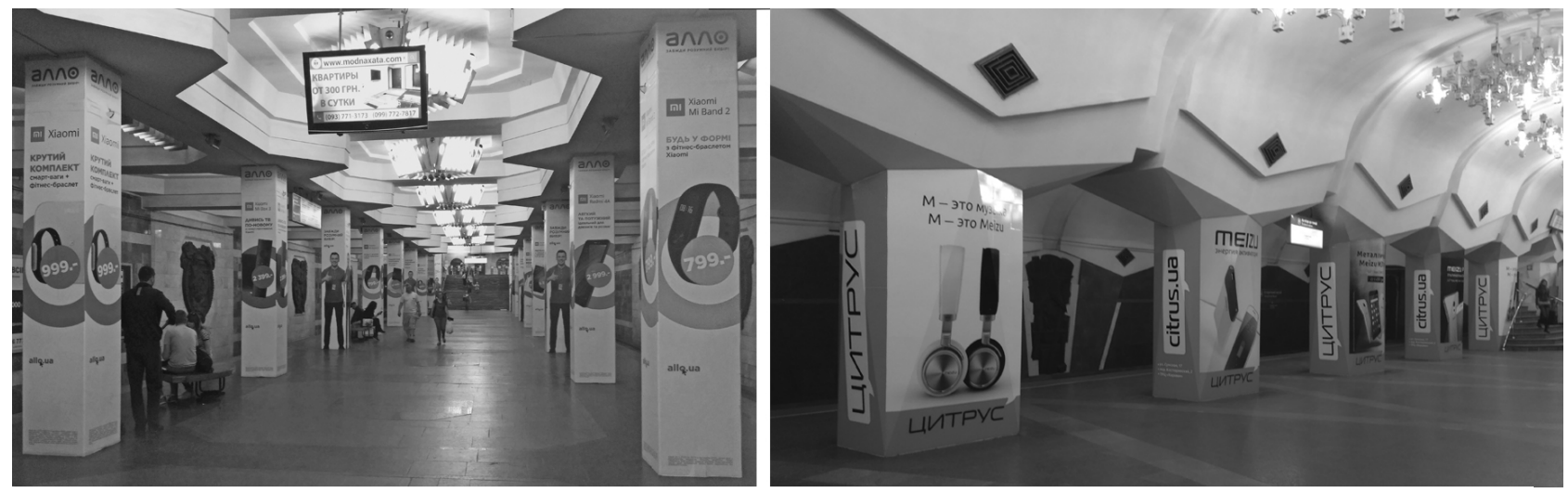

Рис. 2 Реклама брендов «Алло» и «Цитрус» на станцияХ «Героев Труда» и «Исторический музей» в Харькове

Харьковский метрополитен - это достаточно значимый подземный транспортный объект. В Советском союзе он стал шестым по времени открытия, а рейтинг 2000 года среди метрополитенов стран СНГ вывел харьковский метрополитен по показателям длины эксплуатируемых линий на четвертое место после Москвы, Санкт-Петербурга и Киева [5]. На данный момент по протяженности и количеству станций (для предмета данного исследования этот показатель наиважнейший) это четвертое место сохраняется. В 2000 году Харьков располагал 26-ю станциями метрополитена общей протяженностью линий - 33 км. Сейчас действует 30 станций и две в стадии строительства, протяженность пути - более 38 км. Из ближайших по рейтингу конкурентов: Минск имел 22 км пути, сейчас - 37,3 при 29 станциях [6]. Ташкент: 30 км в 2000 г., - 36,2 км и 29 станций по данным на ноябрь 2017 года [7]. Баку: было 29 км, стало 36,6 км и 25 станций [8]. Тбилиси: в рейтинге 2000 г. и по сегодняшний день имеет протяженность эксплуатируемого пути 27 км при 22х станциях [9]. Возникает неприятное предчувствие относительно лидерства харьковского метрополитена в неофициальном антирейтинге среди стран бывшего Советского Союза по количеству рекламы. Проведем анализ.

В России на сегодняшний день метрополитен существует в 7-ми городах: Москве, Санкт-Петербурге, Нижнем Новгороде, Казани, Новосибирске, Самаре и Екатеринбурге. Контент портала рекламного агентства «Аташе» полностью посвящен рекламе в метро российских городов [10]. Изучение материалов, освещающих рекламу метрополитенов Екатеринбурга, Новосибирска, Нижнего Новгорода, Самары и Казани фактов брендирования станций не выявило, не дал «положительных» результатов и целевой серфинг по просторам интернета. Метрополитен Санкт-Петербурга ограничивается размещением на станциях станционных рекламных носителей в виде лайтпостеров. Брендирование как прием сплошного заклеивания 
поверхности одним рекламным сюжетом применяется в переходах и в офрормлении вагонов [11].

Что касается Москвы, здесь остановимся несколько подробнее. На сайте студии дизайна «Дигимак» сообщается о проведенных в 2015 году исследователями отрасли интервью и телефонных опросах для определения эффективности рекламы в московском метро [12]. Согласно статистике, наиболее востребованными рекламными конструкциями стали стикеры в вагонах поездов и рекламные щиты различных фрорматов. В качестве возможных эфффективных видов рекламы на станциях упоминаются постеры на путевых стенах, в вестибюлях и стенах лестничных маршей, лайтбоксы, рекламные щиты (разных типов), фолаги, щиты на эскалаторах, брендирование вагонов поездов, напольная графика, реклама на дверях выхода на станцию и реклама на турникетах. Как видно, брендирование станций не упоминается. Все же удалось отыскать брендирование как средство рекламного оформления. Портал «Реклама в метро» предлагает брендирование станций московского метрополитена, обещая WOWэфффект. Причем в качестве иллюстрации разместили фото станции «Льва Толстого» в Киеве [13]. Рекламное агентство «Еurope Advertizing» представила визуализации вариантов брендирования станций, на которых рекламные сюжеты все же не закрывают полностью опоры, а изображены в виде постеров ограниченной площади. Стоимость, кстати, выставлена как 20000 руб. за кв. м [14]. Ha сайте группы компаний «Мособлрекламы» выставлены предложения брендирования переходов между станциями, а также указан прайс полной стоимости акции от минимального 3 млн. 500 руб. на станциях Римской и Китай-город (150 м²) до 10 млн. руб. на станции Театральная (250 $\left.\mathrm{m}^{2}\right)$ [15]. На станциях метрополитенов Баку, Ташкента, Тбилиси, Еревана и Алматы рекламу можно увидеть только на путевых стенах. А вот в минском метрополитене удалось обнаружить брендирование переходов и четырех станций колонного типа - на опорах были нанесены постеры бренда Coca-cola, официального спонсора Олимпиады в Лондоне, проходила эта акция в 2012 году во время игр [16].

В Украине три города имеют метро. Киев, Харьков и Днипро. Днепровский метрополитен, самый молодой и, соответственно, самый неразветвленный, имеет всего две станции (колонного и пилонного типа), где бы теоретически могла быть расклеена реклама, но ее там нет. В харьковском метро кроме пяти упомянутых выше станций обнаружено еще две («Южный вокзал» ранее и «Проспект Гагарина» в данный момент), которые несли или несут на своих колоннах и пилонах рекламу бренда. Из 30-ти станций брендировано семь. Остается Киев. 
Рекламные операторы наперебой расписывают перед потенциальным заказчиком привлекательность такого вида рекламы: «Брендирование станций и переходов метро - один из самых ярких и оригинальных видов визуальной рекламы в метрополитене. Для Вашей рекламной кампании будет использовано до 1000 квадратных метров поверхности стен, колонн и пола. Это достаточно дорогой и элитный вид размещения рекламы в метро! Ваше присутствие в метро будет замечено абсолютно всеми киевлянами и гостями столицы» (Рекламное агентство «777»); «Брендирование станций - самый впечатляющий и эффективный вид размещения рекламы в метрополитене. Благодаря удачной концепции и оригинальному оформлению, привычный вид станции можно изменить до неузнаваемости, создать неповторимую атмосферу и вызвать нужные эмоции у вашей целевой аудитории (рекламный холдинг «Megapolis»), а креативная концепция брендирования станции от Brave Branding «Водный мир» заняла 1 место на Киевском международном форуме рекламы.

Многие станции киевского метрополитена глубокого заложения пилонного типа (пересадочные узлы «Площадь Льва Толстого» и «Дворец спорта» имеют глубину залегания более 70-ти м), они очень удобны для размещения рекламы, а традиции брендирования оказались давними и устойчивыми. На своей странице в ФБ компанияоператор «Атлантис Люкс», основной деятельностью, которой является размещение рекламы в киевском метрополитене, публикует фото реализации различных рекламных кампаний в метро. Уже в июле 2011 г. в альбоме «брендирование станций» размещены фото 6-ти станций. Всего удалось зафиксировать в заклеенном виде станции «Либідьська», «Почайна», «Льва Толстого», «Палац спорту», «Печерська», «Олімпійська», «Київський політехнічний інститут», «Лук'янівська» [17]. Дизайнер из Киева Богдан Гдаль 16 апреля 2018 года на своей странице в facebook опубликовал фото станций «Палац Україна», «Палац спорту», «Театральна», «Олімпійська» та площа Льва Толстого, которые невозможно узнать из-за засилья рекламы [18]. Благодаря этому можно установить, что, по крайней мере, десять станций киевского метрополитена в то или иное время были брендированы. Таким образом, первенство в абсолютном количестве принадлежит Киеву (десять станций из 52-х в Киеве против семи из 30ти в Харькове, колонного типа киевских - три, харьковских - четыре). В общем, в обоих городах 20\% станций заклеиваются, причем наличие постеров и лайтбоксов на подходах к станции, на путевых стенах, на сводах эскалаторов не в счет - они присутствуют на всех станциях.

Пост Богдана Гдаля о рекламе в метро с негативным комментарием ретранслировали некоторые порталы, что свидетельствует об определенной поддержке данной критической 
точки зрения как со стороны горожан, так и со стороны редакторов интернет-изданий. Дабы перегружать и так наполненный ссылками текст, перечислим лишь некоторые заголовки: «Киевлянина возмутило засилье рекламы в киевском метро», «В сети возмущены засильем рекламы в киевском метро»; «Рекламобесие». Киевляне - о городской подземке»; «Киевляне в сети обсуждают изуродованные агрессивной рекламой станции столичного метро»; «Пробили дно»: киевлян возмутили изуродованные станции метро»; «Подземный террор: как реклама уродует киевское метро» .

Однако надо признать - кое-какие тенденции к исправлению сложившейся ситуации все-таки имеются. Не смотря на то, что метрополитен финансово заинтересован в продаже своих площадей за рекламу, придется поумерить аппетит. В 2017 г. киевский городской совет одобрил новый порядок размещения информационных носителей. Раскрывая основные итоги действия Правил размещения наружной рекламы, и. о. директора КП «Киевреклама» Александр Смирнов отметил необходимость формирования порядок размещения рекламы в метрополитене: «На исторических станциях-памятниках точно не может быть рекламы, на остальных - в минимально необходимом количестве. И обязательно уйдем от ужасной практики брендирования станций. Под рекламными наклейками - шикарное каменное покрытие. Мы должны гордиться и оберегать интерьеры станций. Реклама может быть исключительно на специализированных, сделанных под эти цели локациях. Для каждой станции будут определены тип и место рекламных носителей» [19]. В Харькове, к сожалению, таких тенденций не выявлено.

Выводы. Брендирование станций приводит к уничтожению архитектурного замысла авторов сооружения, к попранию их авторских прав, в итоге - к искажению архитектурного образа. Страдают основополагающие законы архитектурной композиции - тектоника, пропорции, масштаб, пластика. Вместо лаконичности, строгости, простоты и торжественности, чего добивались авторы, возникли эфрфекты карнавала, немасштабные человеку и архитектурному пространству изображения, несочетающиеся с окружением колористические отношения, полиграфические краски в интерьере, ощущение задекорированного забора, за которым производят ремонтные работы.

Приходится с прискорбием признать, что безобразная, бескультурная практика заклеивания мраморных поверхностей рекламной пленкой присуща исключительно двум метрополитенам планеты - киевскому и харьковскому. Материальный стимул здесь очевиден и понятен. Моральный же аспект данного явления взывает к нетерпимости к фактам экспансии рекламных изображений в архитектурное пространство. Специалистам в области архитектуры и 
дизайна совместно с общественно-активной частью населения необходимо активизировать свои действия с целью актуализации данной проблемы и недопустимости такой практики.

\section{Лumepamypa:}

1. Авербах М.Я. Щодо питань про співіснування реклами та архітектури. Архітектурний вісник КНУБА: науково-виробничий збірник. Вип. 11-12. Київ: КНУБА, 2017. С. 264-274;

2. Реклама в метро. Оператор наружной рекламы LifeMedia [Электронный ресурс] - Режим доступа: http://www.lifemedia.kiev.ua/services/reklama-v-metro/ - [Доступ 06.07.2018];

3. Реклама на транспорте. Рекламное агентство «Капитан» [Электронный ресурс] - Режим доступа: http://www.kapitan.kh.ua/services/9-reklama-v-metro/ - [Доступ 06.07.2018];

4. Авербах М. Я. Брендування станцій харківського метрополітену. Погляд з позиції архітектора. Науковий вісник будівництва: збірник наукових праць ХНУБА № 3 (93). Харків: ХНУБА, 2018. С. 10-18;

5. Рейтинги метрополитенов стран СНГ в 2000 году. Московское метро. Проект Артемия Лебедева [Электронный ресурс] - Режим доступа: http://www.metro.ru/library/analytics/604/ - [Доступ 17.06.2018]; 6. Метро сегодня. Официальный сайт минского метрополитена [Электронный ресурс] - Режим доступа: http://metropoliten.by/o_metropolitene/metro_today/ - [Доступ 17.06.2018];

7. Ташкентский метрополитен: 40 лет движения вперёд [Эл ресурс] - - Режим доступа: http://www.metrotashkent.narod.ru/articles/101117.htm/ - [Доступ 17.06.2018];

8. Бакинский метрополитен [Электронный ресурс] - Режим доступа: http://www.metro.gov.az/ru/history/ - [Доступ 17.06.2018];

9. Подробная информация о Тбилисском метрополитене Международная Ассоциация «Метро» [Электронный ресурс] - Режим доступа: http://www.asmetro.ru/metro/metro/tbilisi/tbilisi_full/ - [Доступ 17.06.2018];

10. Реклама в метро [Электронный ресурс] - Режим доступа: http://reklama-vmetro.ru/ - [Доступ 17.06.2018];

11. Брендирование в метро. Реклама в метро Санкт-Петербурга [Электронный ресурс] - Режим доступа: http://www.metrospb.ru/brendirovanie/ - [Доступ 17.06.2018];

12. Реклама в метро. «Digimac» - Креативное агентство [Электронный ресурс] - Режим доступа: http://digimac.ru/blog/reklama/reklama-v-metro/ - [Доступ 17.06.2018]; 
13. Брендирование станций Московского метро. Реклама в метро Москвы [Электронный ресурс] - Режим доступа: http://www.metromsk.ru/brendirovanie/brendirovanie-stancij.htm/ - [Доступ 17.06.2018];

14. Брендирование переходов. Рекламное агентство Europe Advertizing [Электронный ресурс] - Режим доступа: http://www.euroadv.ru/advertising-in-metro/visualization-of-branding-transitions-in-thesubway/ - [Доступ 17.06.2018];

15. Реклама в метро Москвы, цены на 2018 год. Агенство наружной рекламы [Электронный ресурс] - Режим доступа: https://mosoblreclama.ru/auxpage_reklama-v-metro/ - [Доступ 17.06.2018];

16. Откуда в Минском метро «космический» переход между станциями? «Аргументы и Факты в Белоруссии» [Электронный ресурс] - Режим доступа: http://www.aif.by/dontknows/_otkuda_v_minskom_metro_kosmicheskiy_per ehod_mezhdu_stanciyami_/_[Доступ 17.06.2018];

17. Компания «Атлантис Люкс» [Электронный ресурс] - Режим доступа:

https://www.facebook.com/pg/atlantis.lux/photos/?ref=page_internal/ [Доступ 17.06.2018];

18. Богдан Гдаль [Электронный ресурс] - Режим доступа: https://www.facebook.com/viterzbayraku/ - [Доступ 17.06.2018];

19. Станции киевского метрополитена избавят от рекламы [Электронный ресурс] - Режим доступа: http://abcnews.com.ua/ru/business/stantsii-kiievskogho-mietropolitienaizbaviat-ot-rieklamy/ - [Доступ 17.06.2018]. 